\title{
Quality of life of glaucoma patients under medical therapy with different prostaglandins
}

This article was published in the following Dove Press journal:

Clinical Ophthalmology

29 October 2012

Number of times this article has been viewed

\author{
Ricardo Augusto Paletta \\ Guedes ${ }^{1-3}$ \\ Vanessa Maria Paletta \\ Guedes ${ }^{1-3}$ \\ Sirley Maria Freitas ${ }^{2}$ \\ Alfredo Chaoubah' \\ 'Federal University of Juiz de Fora, \\ Juiz de Fora, Minas Gerais, Brazil; \\ ${ }^{2}$ Paletta Guedes Ophthalmological \\ Center, Juiz de Fora, MG, Brazil; ${ }^{3}$ Santa \\ Casa de Misericórdia Hospital, Juiz de \\ Fora, Minas Gerais, Brazil
}

Correspondence: Ricardo Augusto

Paletta Guedes

Av Rio Branco 2337/807, Centro Juiz de

Fora - Minas Gerais, 360 I0-905, Brazil

Tel +55323213 1927

Fax +553232131927

Email palettaguedes@yahoo.com
Purpose: To assess the quality of life of glaucoma patients under medical therapy with different prostaglandin analogs.

Methods: A cross-sectional study of consecutive glaucoma patients was designed. We assessed the patients' quality of life through the Brazilian 25-question version of the National Eye Institute Visual Functioning Questionnaire, comprising 12 subscales (general health, general vision, ocular pain, near vision, distance vision, social function, mental health, role limitations, dependency, driving, color vision, and peripheral vision) and a total composite score. Clinical features, including current medical treatment, were obtained from each patient's medical record. Three groups of patients were identified according to the prostaglandin in use: bimatoprost, latanoprost, or travoprost. The main outcome measures were: mean score in each subscale and mean total composite score.

Results: The mean total composite score for the whole group was 70.60 . The bimatoprost, latanoprost, and travoprost groups had the following mean composite scores, respectively: $56.56,77.36$, and $71.08(P=0.001$, analysis of variance [ANOVA]). Latanoprost and travoprost results were similar, and both were superior to bimatoprost. Most subscales had similar results. The subscale with the lowest score for all groups was general health. Groups were homogenous and comparable.

Conclusion: There is a difference in the quality of life between glaucoma patients using prostaglandin analogs. It seems that bimatoprost users have lower QoL when compared to latanoprost and travoprost users.

Keywords: glaucoma, medical treatment, prostaglandin analogs, quality of life

\section{Introduction}

Glaucoma is the leading cause of irreversible blindness in the world. ${ }^{1}$ The main goal of glaucoma treatment is to maintain the patient's quality of life $(\mathrm{QoL})$, which includes preservation of visual function, at a sustainable cost. ${ }^{2}$

Individuals diagnosed with glaucoma can lose QoL for several reasons: worry and anxiety due to diagnosis of a chronic illness, functional loss, the inconvenience of the treatment, side effects, and cost of the therapy. ${ }^{2}$

Medications are the most important tool to stop the progression of glaucomatous optic neuropathy, by reducing the intraocular pressure to a safe level (target pressure). Glaucoma medications may influence an individual's QoL in different manners: ${ }^{3}$ daily use of medications reminds patients of their medical condition; glaucoma drops may be expensive and difficult to administer; local and systemic side effects may affect their vision and life; dosing schedules may interfere with their activities; patients might 
become concerned and anxious about whether they are properly using their drops. ${ }^{3}$

The class of prostaglandin analogs has become the most commonly prescribed medical treatment for glaucoma. ${ }^{4}$ The three representatives of this class that are most-used around the world are bimatoprost, latanoprost, and travoprost. They remain the most effective drugs for reducing intraocular pressure, leading to approximately $30 \%$ reduction from pretreatment levels. ${ }^{4}$ Many studies have proved these drugs' efficacy and tolerability in different populations; ${ }^{4}$ however, local side effects are considerably different among the different types of prostaglandins. ${ }^{4,5}$ Bimatoprost is known to present the highest incidence of local side effects among all prostaglandins, while latanoprost presents the lowest rate of local side effects. ${ }^{4,5}$

Few studies directly addressed the effects of glaucoma medications on QoL using standardized instruments. ${ }^{6,7}$ Our purpose is to assess the QoL of glaucoma patients under topical therapy with different prostaglandin analogs (bimatoprost, latanoprost, and travoprost) through the 25-question Brazilian version of the National Eye Institute Visual Functioning Questionnaire (NEI VFQ-25) and see if there is any difference in QoL perceived by the patient.

\section{Materials and methods}

Consecutive glaucoma patients from the office practice of two of the authors (RAPG and VMPG) were recruited for this cross-sectional study. Inclusion criteria were adult glaucoma patients with reliable results in the visual field test and with at least 3 months under the same topical therapy. Reliable visual-field testing was defined as less than $25 \%$ fixation errors, $25 \%$ false negatives, and $15 \%$ false positives. The exclusion criterion was any ocular surgery (including filtering surgery) during the past 6 months.

The following clinical variables were obtained from the medical records: age, gender, type of glaucoma, stage of glaucoma (based on the Hodapp, Parish, and Anderson criteria $^{8}$ for a visual-field staging system), visual acuity (categorized into three groups: $>0.5$; between 0.5 and 0.1 , and $<0.1$ ); current glaucoma therapy; history of previous filtering surgery; systemic comorbidity (diabetes, cardiovascular disease, asthma, cancer); and ocular comorbidity (cataract, corneal diseases, retinal vascular diseases) in the eye with better visual acuity and in the eye with the worst visual acuity.

In order to assess the patients' QoL, we chose to use the validated Portuguese-language version for Brazil of the NEI VFQ-25. ${ }^{9}$ A trained person (SMF) performed all interviews.
This questionnaire addresses aspects of visual ability on 12 subscales, which includes general health, general vision, ocular pain, near vision, distance vision, social function, mental health, role limitations, dependency, driving, color vision, and peripheral vision. Each subscale has questions with five possible answers ranging from 1 to 5 or 6 . Each subscale was converted to a possible score ranging from 0 to 100 , with a higher score indicating better QoL. A composite score, which was the mean score of all subscales, was also calculated.

Comparisons between variables were done using a Chi-square test (categorical variables) and an analysis of variance (ANOVA) test (numerical variables) with a significance of $95 \%$. Statistical analysis was performed using SPSS 13.0 (SPSS Inc, Chicago, IL).

This study was approved by the Ethics Committee of the Federal University of Juiz de Fora and adhered to the tenets of the Declaration of Helsinki. Informed consent was obtained from each individual participating in this study.

\section{Results}

Two-hundred thirteen glaucoma patients were interviewed from May 2010 to October 2010. Of these, 167 (78.4\%) were in medical treatment and met the inclusion criteria for this study. One hundred seventeen out of the 167 (70.1\%) were chronic users of one of the prostaglandin analogs. Bimatoprost was used by $18.8 \%$ (22/117) of the patients, latanoprost by $35.9 \%$ (42/117), and travoprost by $45.3 \%$ (53/117).

The majority of the population studied was primary openangle glaucoma patients $(n=92)$, followed by angle-closure glaucoma patients $(n=14)$ and patients with other types of glaucoma $(n=11)$. Table 1 presents the clinical characteristics of the groups studied (bimatoprost, latanoprost, and travoprost). No statistical differences existed between the three groups for the clinical features, except for a marginal significance for sex. No differences between groups were found concerning the assessment of systemic comorbidity $(P=0.517$, ANOVA $)$ or ocular comorbidity $(P=0.844$ [ANOVA] for the better-seeing eye and $P=0.590$ [ANOVA] for the worse-seeing eye).

Patients using prostaglandin drops often need another medication as adjunctive therapy. Table 2 presents the proportion of patients using another medication (beta blockers, alpha-2 agonists, or carbonic anhydrase inhibitors) in each group. None of the patients concomitantly used a myotic with their prostaglandin analog. A higher proportion of patients using bimatoprost were also using an alpha-2 agonist $(P=0.001$, ANOVA $)$. 
Table I Characteristics of the population studied $(\mathrm{n}=117)$

\begin{tabular}{|c|c|c|c|c|}
\hline Characteristics & $\begin{array}{l}\text { Bimatoprost } \\
(n=22)\end{array}$ & $\begin{array}{l}\text { Latanoprost } \\
(n=42)\end{array}$ & $\begin{array}{l}\text { Travoprost } \\
(n=53)\end{array}$ & $P$ \\
\hline Mean age (years) & 66.09 & 62.38 & 67.55 & $0.27 I^{\mathrm{a}}$ \\
\hline \multicolumn{5}{|l|}{ Sex } \\
\hline Male $(n=48)$ & $54.5 \%$ & $50.0 \%$ & $28.3 \%$ & $0.037^{b}$ \\
\hline Female $(n=69)$ & $45.5 \%$ & $50.0 \%$ & $71.7 \%$ & \\
\hline \multicolumn{5}{|l|}{ Race } \\
\hline White $(n=8 I)$ & $59.0 \%$ & $73.8 \%$ & $69.8 \%$ & $0.577^{\mathrm{b}}$ \\
\hline Black $(n=2 I)$ & $31.8 \%$ & $11.9 \%$ & $17.0 \%$ & \\
\hline $\operatorname{Mixed}^{c}(n=15)$ & $9.2 \%$ & $14.3 \%$ & $13.2 \%$ & \\
\hline \multicolumn{5}{|l|}{ Type of glaucoma } \\
\hline POAG $(n=92)$ & $90.9 \%$ & $71.4 \%$ & $79.2 \%$ & $0.072^{\mathrm{b}}$ \\
\hline ACG $(n=14)$ & $0.0 \%$ & $11.9 \%$ & $17.0 \%$ & \\
\hline Other $(n=I I)$ & $9.1 \%$ & $16.7 \%$ & $3.8 \%$ & \\
\hline \multicolumn{5}{|l|}{ Stage of glaucoma } \\
\hline Early $(n=79)$ & $50.0 \%$ & $69.0 \%$ & $73.6 \%$ & $0.150^{\mathrm{b}}$ \\
\hline Moderate $(n=13)$ & $9.1 \%$ & $14.3 \%$ & $9.4 \%$ & \\
\hline Advanced $(n=25)$ & $40.9 \%$ & $16.7 \%$ & $17.0 \%$ & \\
\hline \multicolumn{5}{|l|}{ VA in better eye } \\
\hline$>0.5(n=95)$ & $72.7 \%$ & $78.6 \%$ & $86.8 \%$ & $0.484^{b}$ \\
\hline $0.5-0.1(n=20)$ & $22.7 \%$ & $19.0 \%$ & $13.2 \%$ & \\
\hline$<0.1(\mathrm{n}=2)$ & $4.6 \%$ & $2.4 \%$ & $0.0 \%$ & \\
\hline
\end{tabular}

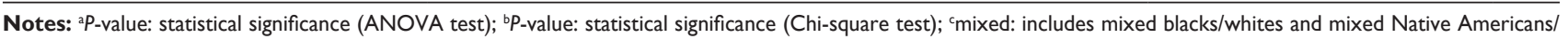
whites; dglaucoma stage based on the Hodapp, Parish, and Anderson staging system.

Abbreviations: POAG, primary open-angle glaucoma; ACG, angle closure glaucoma; VA, visual acuity.

The mean total score (composite score) for all prostaglandin users was 70.60. Figure 1 illustrates the results for the composite score for each prostaglandin group. The bimatoprost group had the lowest score: 56.56; latanoprost presented the highest score: 77.39; and travoprost scored 71.08 ( $P=0.001$, ANOVA). In a post hoc evaluation using the Tukey's HSD test, we were able to find evidence that there was no statistical difference between the scores for the latanoprost and travoprost groups and that both were superior to the bimatoprost group.

Bimatoprost had the lowest composite score, and it was also the group with highest proportion of adjunctive alpha-2agonist users. In order to clarify this question, we decided to evaluate the total composite QoL score in the whole medical therapy group $(\mathrm{n}=167)$, separating them into two groups: one with and the other without alpha- 2 agonist. We performed this same evaluation for each prostaglandin analog. Table 3 shows these results. No differences were observed for alpha-2 agonists and travoprost composite scores. The presence of bimatoprost led to a worse score, while the presence of latanoprost led to a better one.

The mean scores for each subscale of the questionnaire are presented in Table 4.

\section{Discussion}

Our results showed differences in the QoL, measured by the NEI VFQ-25, in a group of prostaglandin users who were glaucoma patients. It seems that bimatoprost users have a lower QoL when compared to latanoprost and travoprost users.

In most studies assessing QoL and glaucoma medications, QoL is indirectly mentioned in the reporting of side effects. Few studies directly addressed the effects of glaucoma medications on QoL using standard instruments. Balkrishnan et al, using the NEI VFQ-25 questionnaire, found that the difficulty in using eye drops was strongly associated with a decrease in QoL.?

Table 2 Proportion of adjunctive therapy in each group

\begin{tabular}{lllll}
\hline Medication & Bimatoprost & Latanoprost & Travoprost & $\boldsymbol{P}^{\mathbf{a}}$ \\
\hline Topical beta-blocker $(\mathrm{n}=72)$ & $25.0 \%$ & $33.3 \%$ & $41.7 \%$ & 0.095 \\
Topical alpha-2 agonist $(\mathrm{n}=28)$ & $42.9 \%$ & $28.6 \%$ & $28.6 \%$ & 0.001 \\
Topical CAI $(\mathrm{n}=29)$ & $31.0 \%$ & $20.7 \%$ & $48.3 \%$ & 0.060 \\
Systemic CAI $(\mathrm{n}=2)$ & $0.0 \%$ & $50.0 \%$ & $50.0 \%$ & 0.777 \\
\hline
\end{tabular}

Note: ${ }^{a} P$-value: statistical significance (ANOVA test).

Abbreviation: $\mathrm{CAl}$, carbonic anhydrase inhibitors. 


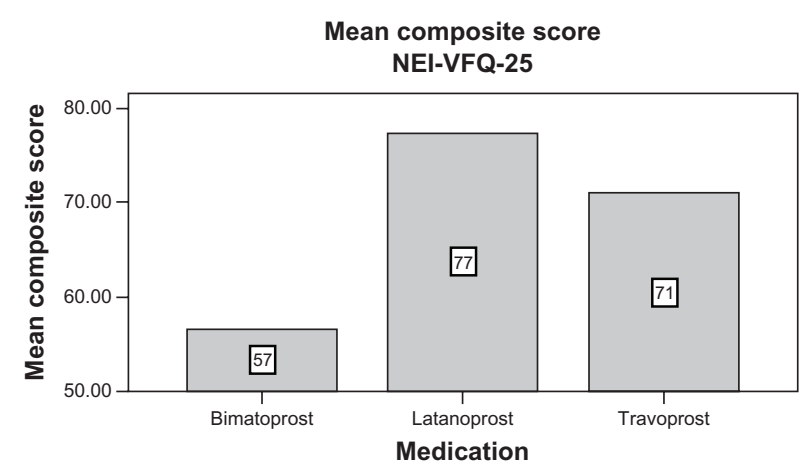

Figure I Results for the mean composite score in each group. Abbreviation: NEI VFQ-25, National Eye Institute Visual Functioning Questionnaire.

In this study, we used the NEI VFQ-25 to evaluate the QoL of glaucoma patients under medical treatment. This is the most widely used eye disease-specific, health-related QoL instrument, and it has been translated and validated for the Brazilian population. ${ }^{9}$ Most of the subscale scores were significantly different among the three groups, and were in agreement with the mean total composite score. This demonstrates that there is not a specific subscale involved in our results. The lowest subscale score for all three groups was general health. This result accords with previous findings in the literature. Sawada et al found that general health had the lowest scores for both young and old groups of glaucoma patients, concluding that this may reflect the psychological burden experienced by glaucoma patients. ${ }^{10}$

We decided to exclude patients who had had filtering surgery for the past 6 months, because surgery could have altered the patient's QoL, as observed in the Collaborative Initial Glaucoma Treatment Study. ${ }^{11}$

The composite score for the whole group (all prostaglandin users) was 70.60. Latanoprost users had the highest score (77.39), followed by travoprost (71.08) and bimatoprost (56.56). Latanoprost and travoprost showed similar results in QoL, and both were superior to bimatoprost. To our knowledge, this is the first study to demonstrate such differences in patients' QoL.

Table 3 Mean composite score according to the presence and absence of different glaucoma medications for the whole medical treatment group $(n=167)$

\begin{tabular}{llll}
\hline Medication & Present & Absent & $\boldsymbol{P a}$ \\
\hline Topical alpha-2 agonist & 66.49 & 71.88 & 0.165 \\
Bimatoprost & 56.58 & 72.79 & 0.001 \\
Latanoprost & 77.39 & 68.39 & 0.016 \\
Travoprost & 71.03 & 70.48 & 0.877 \\
\hline
\end{tabular}

Note: aP-value: statistical significance (ANOVA test).
Table 4 Subscale scores for each group

\begin{tabular}{lllll}
\hline Subscale & $\begin{array}{l}\text { Bimatoprost } \\
(\mathbf{n}=\mathbf{2 2})\end{array}$ & $\begin{array}{l}\text { Latanoprost } \\
(\mathbf{n}=\mathbf{4 2})\end{array}$ & $\begin{array}{l}\text { Travoprost } \\
(\mathbf{n}=\mathbf{5 3})\end{array}$ & $\mathbf{P}^{\mathbf{a}}$ \\
\hline General health & 44.32 & 61.91 & 45.76 & $<0.00 \mathrm{I}$ \\
General vision & 67.27 & 75.24 & 72.45 & 0.164 \\
Ocular pain & 67.05 & 72.32 & 74.29 & 0.503 \\
Near vision & 53.03 & 79.37 & 72.01 & 0.001 \\
Distance vision & 51.33 & 78.57 & 67.45 & 0.001 \\
Social function & 64.21 & 87.20 & 76.89 & 0.003 \\
Mental health & 48.01 & 71.49 & 68.04 & $<0.001$ \\
Role limitations & 45.46 & 79.17 & 70.28 & 0.001 \\
Dependency & 57.58 & 86.31 & 88.08 & 0.001 \\
Driving & 63.89 & 75.25 & 70.83 & 0.674 \\
Color vision & 73.86 & 94.05 & 87.74 & 0.015 \\
Peripheral & 51.14 & 69.64 & 66.98 & 0.044 \\
vision & & & & \\
\hline Note: & & &
\end{tabular}

Note: aP-value: statistical significance (ANOVA test).

Age, race, type of glaucoma, glaucoma stage, and visual acuity in the better-seeing eye were not different between the groups studied. They are confounding variables, potentially. Many studies have demonstrated that the more advanced the glaucoma, the worse the patient's QoL. ${ }^{10,12}$ Others have shown that the visual acuity in the better eye is a great predictor of a patient's QoL. ${ }^{13}$ These issues were not problems in our study, as all the groups studied were homogenous. One exception was for gender. There was a higher proportion of females in the travoprost group, but the significance of that difference was not strong.

The difference in the QoL score results is not explained by any comorbidity, whether systemic or ocular. It was also not due to adjunctive therapy accompanying the prostaglandin analog. Although we observed a higher proportion of patients under bimatoprost, who were also using a topical apha-2 agonist, this did not influence the QoL results, because the presence or absence of the latter did not change the composite score. Conversely, the presence of bimatoprost led to a decline in the QoL score (72.79 for patients without bimatoprost vs 56.58 for those on bimatoprost), reaffirming that bimatoprost was responsible for the change in QoL.

Among the three prostaglandin analogs, bimatoprost is believed to yield a slightly better result in terms of intraocular pressure reduction and the cost-effectiveness ratio. ${ }^{4,14}$ However, Reardon et al demonstrated that it had the poorest persistency profile. ${ }^{15}$ This poor persistency can in part be explained by our QoL results.

Latanoprost is known for its efficacy, safety, and very few side effects. ${ }^{6}$ According to a recent study, it has the highest persistency rate among the glaucoma medications. ${ }^{16}$ In our study, putting a patient on latanoprost can actually increase 
their QoL (77.39 vs 68.39). A better QoL score can lead to a higher persistency rate.

In our study, travoprost had QoL results similar to those from latanoprost. Prescribing travoprost to a glaucoma patient will not interfere with his or her QoL (70.48 vs 71.03). In the literature, travoprost reportedly has efficacy and tolerability results similar to those of the other two prostaglandins. ${ }^{17}$

Interestingly, the better QoL results of latanoprost and travoprost were not due to the ocular pain subscale, which could capture the local side effects and discomfort caused by the topical treatment. It was one of the few subscales that did not differ between the three groups. A possible explanation is that, although the local side effects were present more in the bimatoprost users, it does not directly influence QoL, per se. However, these side effects can lead to a worse self-perception of the severity of the disease. This can cause a psychological burden that influences the patient's QoL.

Our study had some limitations. Patients using preserved medications, such as, in Brazil, preservative-free or BAK-free prostaglandin analogs, were not available at the time of the study. Preservative-free medications tend to correlate with a better tolerability profile, possibly enhancing patients' perceived QoL. ${ }^{18}$ Also, bimatoprost was $0.03 \%$. During our study, bimatoprost $(0.01 \%)$ was not available for use.

Another study limitation that might have influenced our results was that patients were not randomly assigned to receive one of the drugs studied, as this was a cross-sectional study and patients were already using the medication. Although we tried to control for the possible confounding variables (glaucoma stage, visual acuity in the better-seeing eye, etc), there could be a selection bias based on a doctor's personal decisions and beliefs. We recommend these findings be validated by a randomized, controlled trial.

In conclusion, our study suggests that the QoL among glaucoma patients using prostaglandin analogs is not uniform. Patients using bimatoprost had a lower perceived QoL, while latanoprost and travoprost users had a similar perceived QoL.

\section{Disclosure}

The authors report no conflicts of interest in this work.

Clinical Ophthalmology

\section{Publish your work in this journal}

Clinical Ophthalmology is an international, peer-reviewed journal covering all subspecialties within ophthalmology. Key topics include: Optometry; Visual science; Pharmacology and drug therapy in eye diseases; Basic Sciences; Primary and Secondary eye care; Patient Safety and Quality of Care Improvements. This journal is indexed on Submit your manuscript here: http://www.dovepress.com/clinical-ophthalmology-journal

\section{References}

1. Resnikoff S, Pascolini D, Etya'ale D, et al. Global data on visual impairment in the year 2002. Bull World Health Organ. 2004;82:844-851.

2. European Glaucoma Society. Terminology and Guidelines for Glaucoma, 2nd ed. Savona, Italy: Ed Dogma; 2003.

3. Emerick GT. Quality of life and glaucoma medications. Do our proescriptions make a difference? Glaucoma Today. 2005;5:38-39.

4. Aptel F, Cucherat M, Denis P. Efficacy and tolerability of prostaglandin analogs: a meta-analysis of randomized controlled clinical trials. J Glaucoma. 2008;17:667-673.

5. Honrubia F, Garcia-Sanchez J, Polo V, de la Casa JM, Soto J. Conjunctival hyperaemia with the use of latanoprost versus other prostaglandin analogues in patients with ocular hypertension or glaucoma: a meta-analysis of randomized clinical trials. Br J Ophthalmol. 2009;93: 316-321.

6. Zimmerman TJ, Stewart WC, Latanoprost Axis Study Group. Intra-ocular pressure, safety and quality of life in glaucoma patients switching to latanoprost from monotherapy treatments. J Ocul Pharmacol Ther. 2003;19:405-415.

7. Balkrishnan R, Bond JB, Byerly WG, Camacho FT. Medicationrelated predictors of health-related quality of life in glaucoma patients enrolled in a Medicare health maintenance organization. Am J Geriatr Pharmacother. 2003;1:75-81.

8. Hodapp E, Parrish RK, Anderson DR. Clinical Decisions in Glaucoma. St Louis, MO: Mosby; 1993.

9. Simao LM, Lana-Peixoto MA, Araújo CR, Moreira MA, Teixeira AL. The Brazilian version of the 25-item National Eye Institute Visual Function Questionnaire: translation, reliability and validity. Arq Bras Oftalmol. 2008;71:540-546.

10. Sawada H, Fukuchi T, Abe H. Evaluation of the relationship between quality of vision and visual function in Japanese glaucoma patients. Clin Ophthalmol. 2011;5:259-267.

11. Janz NK, Wren PA, Lichter PR, et al. The Collaborative Initial Glaucoma Treatment Study: interim quality of life findings after initial medical or surgical treatment of glaucoma. Ophthalmology. 2001;108:1954-1965.

12. Ramulu P. Glaucoma and disability: which tasks are affected, and at what stage of disease? Curr Opin Ophthalmol. 2009;20:92-98.

13. Sharma S, Brown GC, Brown MM, et al. Converting visual acuity to utilities. Can J Ophthalmol. 2000;35:267-272.

14. Noecker RJ, Walt JG. Cost-effectiveness of monotherapy treatment of glaucoma and ocular hypertension with the lipid class of medications. Am J Ophthalmol. 2006;141:S15-S21.

15. Reardon G, Schwartz GF, Mozzafari E. Patient persistency with topical ocular hypotensive therapy in a managed care population. Am J Ophthalmol. 2004;137:S3-S12.

16. Reardon G, Schwartz GF, Kotak S. Persistence on prostaglandin ocular hypotensive therapy: an assessment using medication possession and days covered on therapy. BMC Opthahlmol. 2010;2:10-15.

17. Suzuki ER, Suzuki CL. Efficacy and safety of travoprost alone or in combination with other agents for glaucoma and ocular hypertension: patient considerations. Clin Ophthalmol. 2010;21:1165-1171.

18. Hommer A. A review of preserved and preservative-free prostaglandin analogues for the treatment of open angle glaucoma and ocular hypertension. Drugs Today (Barc). 2010;6:409-416.
PubMed Central and CAS, and is the official journal of The Society of Clinical Ophthalmology (SCO). The manuscript management system is completely online and includes a very quick and fair peer-review system, which is all easy to use. Visit http://www.dovepress.com/ testimonials.php to read real quotes from published authors. 